\title{
EBV-Related Leiomyosarcoma
}

National Cancer Institute

\section{Source}

National Cancer Institute. EBV-Related Leiomyosarcoma. NCI Thesaurus. Code C162306.

Leiomyosarcoma that is caused by Epstein-Barr virus infection. 